Introductory Notes on the Toys and Games of Elema, Papuan Gulf Author(s): J. H. Holmes

Source: The Journal of the Royal Anthropological Institute of Great Britain and Ireland, Vol. 38 (Jul. - Dec., 1908), pp. 280-288

Published by: Royal Anthropological Institute of Great Britain and Ireland

Stable URL: http://www.jstor.org/stable/2843301

Accessed: 29-11-2015 11:47 UTC

Your use of the JSTOR archive indicates your acceptance of the Terms \& Conditions of Use, available at http://www.jstor.org/page/ info/about/policies/terms.jsp

JSTOR is a not-for-profit service that helps scholars, researchers, and students discover, use, and build upon a wide range of content in a trusted digital archive. We use information technology and tools to increase productivity and facilitate new forms of scholarship. For more information about JSTOR, please contact support@jstor.org. 


\title{
INTRODUCTORY NOTES ON THE TOYS AND GAMES OF ELEMA, PAPUAN GULF.
}

\author{
By the Rev. J. H. Holmes,
}

Local Correspondent of the Royal Anthropological Institute.

Toys.

1. Ball-tossing.-A game common to the young people of both sexes of all the Elema tribes is ball-tossing.

The names by which the game is known amongst the respective tribes are very dissimilar, but it is interesting to note that, as far as our research has gone, the native and primitive balls used to-day in this game are probably an evolution from a more primitive ball, viz., the bladder of pigs and other animals.

The game is known to the Toaripi tribe as ipa, "bladder"; the Morea-ipi tribe speak of the game as puahoa, the term in their dialect for "bladder."

As in the dissimilarity of terms by which the game is known in Elema likewise in the make of the balls used in the game there is very little resemblance in the materials adopted. The Toaripians procure a hard nut, resembling in size and hardness the betel-nut, known as ferehae, which is obtained from a bastardpalm of that name, and on account of its shape and hardness it is adopted as the centre of the ball. Having procured the ferehae, a large number of fronds from the same species of palm, and known as soe, are picked and tied end to end in reef knots until the requisite length is provided.

With this primitive strapping the ferehae is wound tightly round and round by the boys until they have succeeded in making a ball the size and hardness they require, usually of the size of a cricket ball.

The Morea-ipi boys expend less time and trouble on the balls they make for this game, and they do not seem to attach importance to the game itself, as a season game, as do the Toaripians.

A piece of the stem of the nipa palm, when dry, of the size of a large egg, is cut out to form the centre of the ball, and this is bound tightly in dry banana leaves with the result that an unshapely ball is made.

The ball game is strictly a season game with the Toaripians, i.e., they play it as a game only during the saravera season, that is from the end of April to the middle of June. The Morea-ipians play it at any time and never very enthusiastically.

With our present knowledge of the game as played by the respective tribes of Elema it seems unlikely that any rules are observed; the object of the players 
is to keep the ball bouncing upwards as long as possible, and when it falls to the ground there is a rush for it that it may be tossed up again and kept going with a zest proportionate with the enthusiasm of the players.

2. Apo seika.-Apo seika, literally a small bow, resembles in size the toy bows used by boys in the rural districts of England. It is the ambition of all the small boys to possess a toy bow and a set of arrows. These bows and arrows are usually made by the fathers or male guardians of the boys, and a pliable wood named para (Toaripi), elele (Morea-ipi), is procured for this purpose; occasionally split bamboo may be used for the bow. The bow-string is made from a strip of the rind of rattan cane, and the arrows are usually very sharply pointed midribs from the frond of the sago palm, or, when the boy is getting a big lad and capable to make and discharge a larger arrow, a light wood is used which he whittles, with a knife-if he can get one-or an oyster shell, to the shape and size his fancy suggests.

As a small boy, and whilst he is content to use the midribs of sago palm fronds as arrows, he finds his pleasure in discharging them aimlessly, but on becoming a bigger boy he also becomes ambitious to compete with boys of his age, and sicles are then formed; coconut husks are used as targets, and each boy strives to place the largest number of arrows into the target at a distance fixed by the competitors and increased as thought advisable.

This pastime gives a deal of pleasure, but it is considered by the boys to be inferior to shooting at soft objects buried in the sand. When this kind of shooting is adopted, a sweet potato or taro is buried in the sand, and the boys, standing at a given distance, aim for the hidden object; the best shot being the boy who succeeds in getting the most arrows into the buried target.

Apo seikci as a game or pastime is general among the boys of all Elema tribes, but is, probably, more appreciated by the boys of the Morea-ipi tribe than by the boys of their kindred tribes; as a cornpetitive game the Morea-ipi boys have certainly developed it in many ways unknown to, or at least, not adopted by, the boys of neighbouring tribes.

3. Opi.-Opi is the name of a hard nut which resembles in size and shape a large acorn. It is picked when green and a midrib of the frond of the coconut palm is passed perpendicularly and vertically through until about an inch of the spindle protrudes at the lower end on which the top spins. At the spinning or upper end about 6 inches of the midrib is left, thus providing sufficient to spin the opi or primitive top by chafing it between the palms of the hands to give it velocity.

$O p i$ is also the Toaripi name of the game; the name by which the top and the game are known by the Morea-ipi tribe is porohae. Top-spinning is indulged in by the lads and young men of all the Elema tribes as a pastime for individual amusement, but it is oftener played competitively with the same object as boys have at home, viz., to ascertain whose top will spin the longest period. When played in this way, each competitor provides himself with a scraped out 
piece of coconut shell in the hollow of which he spins his top. When the shells have been sufficiently scraped to provide a smooth surface, the competitors seat themselves in a row and await the signal " $m a, m a, m a ! "$ The significance of this monosyllable is not yet known other than as an abbreviation of mapuso (water), but it is daily used as a call to the pigs when the women wish them to come home to feed.

The season for top-spinning is usually from October to the end of the year among all these tribes.

4. Ori--Ori is the name of the kite made by the Elema tribes; the same term is the general word for bird in all the dialects of these tribes.

There seems to be no fixed design or pattern of kite, the only object being to make something strong enough, yet light enough, to soar as high as wind and string will allow.

The frame-work of the kites made by the Toaripians is usually strong, thin strips of rattan cane, covered either with dressed paper-mulberry cloth or with the sheath fibre thrown off by the young palms of coconut trees.

The kite is known by the same name, ori, by the Morea-ipi tribe, but jts frame-work is made somewhat differently; for rattan cane the midrib of the nipa palm is substituted and covered with coconut fibre, but with so little care that these kites are inferior to those made by the young men and lads of the Toaripi tribe.

The kites are provided with tails, usually a long piece of native twine with strips of dead banana leaves knotted into the twine. The kites when finished, display more ingenuity than art, and are as primitive in design as they are in construction.

Whilst the kites are made by the big lads and young men of the respective. tribes, young and old of both sexes share in the pleasure and excitement of flying them when the south-east monsoon is at its strongest. The cord used for kiteflying is native made; when entbusiasm is high the kite is allowed to soar proportionately high until it gets nearly out of sight, and sometimes it is intentionally set free.

5. Kekesi is a toy very like the paper windmill English children play with. The boys make these themselves from pandanus leaves. [Captain Barton (p. 278) refers to this toy; I obtained one at Hula, where it is called make, and at Mawatta the same toy is known as ve.-A. C. H.]

6. Hockey.-A game closely resembling hockey is played by the young people of all the Elema tribes, but it is probably more highly appreciated and more skilfully played by the young people of both sexes of the Morea-ipi tribe than by any of their kindred tribes. The Toaripians name this game tola fare toai, literally, to hit, drive, or knock the fruit or seed of a tree which is used as a ball in this game.

The Morea-ipians name this game kora hae koaki, which, when translated, has the same meaning as given above, but unlike the Toaripians, they make it a season game; i.e., they only play it during the north-west monsoon season, from November to the end of March, when a hard nut, in shape and size not unlike 
a duck's egg, named hia, is obtainable. The Toaripians have no fixed season for this game, but seem to play it whenever it strikes their fancy, neither have they any particular nut associated with the game.

Another point of difference is noted in the kind of driving-sticks used in playing the game. The Toaripians use straight sticks, usually of a wood named hauta, and preferred for its lightness; failing this particular wood, any other light stick available is used; the Morea-ipians also prefer a light wood for their driving sticks, and always provide themselves with a wood named koai haru, but all their driving sticks have a curve at one end very like the wooden driver used by golfers at home.

To play the game, sides are formed, and goals are fixed, the object being to drive the ball beyond opponents' goal ; this being achieved, the victors cheer lustily and the defeated side takes defeat sadly, but with sportsmanlike courage demands another game with the hope of equalising success.

No change of sides is made for the return game, and, as in most of the competitive games of these tribes, no notice seems to be taken of inequality, in size or number, of competing parties; onlookers help either side as the game progresses, generally the winning side. The Papuan will need to evolve to a much higher plane of manhood ere he can adopt the true sportsman's precept of "give and take."

7. Toy Canoes.-The boys of Elema derive much pleasure, during the northwest season, from making and sailing toy canoes.

These toy canoes are models of the canoes in daily use by the respective tribes of the district; hence it is that the boys of the Toaripi tribe make their toy canoes to represent the double canoes in common use by their own people, whereas the toy canoe of the Morea-ipi boys is a model of the outrigger canoe which is, by the way, of comparatively modern adoption by their tribe. The loti vaki vaki or loti seika-Toaripi names for their toy canoes-of the Toaripi boys, is a fair sample of the workmanship and skill displayed by the boys of all these tribes; their ability to imitate is marked in the manufacture of all their toys, but utter disregard for strength and durability characterises all they do as boys, and much of what they do when they become men.

The stem of the nipa palm is used for the hull of both kinds of toy canoe, double and outrigger, and is so shaped as to distinguish the bows from the stern; the upper or deck part is trimmed to make it flat, but not hollowed, and the whole of the outside is bevelled slightly from the imaginary gunwale to the keel, thus giving the hull a canoe-like appearance.

To make a double canoe, two pieces of the nipa palm stem are cut in equal lengths and skewered together, just below the deck line, but at an equal distance apart, that the desired space between the two canoes may be obtained. The hard stem of the sago palm frond is used for skewers or crosspieces, and in addition to the usual number required, according to the length of the model, to hold the two parts of the hull together, two of these skewers are put across at the stern end, so 
closely as to leave only space enough between them to permit of a small piece of wood being put in to act as an automatic rudder.

A platform, of thin strips of the nipa palm stem, is laid from beam to stern, and in this platform the sago palm stems are stepped as masts, in such number as the boy builder fancies. The sails, palm fronds of any kind, are bent to the masts prior to stepping them, i.e., the masts are passed longitudinally through the frond sails, consequently no binding or lashing is required.

The materials used, and the method of construction pursued in making a toy double-canoe are, in the main, the same, and almost uniformly adopted by the boys of all the Elema tribes; such differences as exist are limited to the particular model adopted.

The hull of the outrigger canoe has only one canoe, and as a toy canoe, its outrigger is not a correct copy of these canoes, as it has only one arm and a float at its far end stuck on in any fashion, whereas the outrigger canoe of daily use has much attention devoted to its outrigger, and displays much skill in native lashing.

8. Musical toys.-In designating these toys as "musical," it will be assumed that the writer is endeavouring to represent what they are to the Elema boys, and not what they might prove to be to a people of a higher civilisation.

These toys are few and very primitive. The most primitive is probably the mouth-organ, which is made by doubling any kind of leaf, and so placing it between the lips that the edges of the bent leaf rest on the teeth. By blowing gently outward and into the hollow of the leaf, a squealing noise is produced, or what may possibly be a musical note to the boys who produce it.

Another primitive instrumeni, made by the boys of all the Elema tribes, is the flute. It is made from a piece of bamboo, about 18 inches in length, and 1 inch in diameter. The interior partitions of the bamboo are forced through when the bamboo is green and soft. A hole may, or may not, be made about 2 inches from one of the ends; when it is made in that position, the performer blows into it, in much the same way as is done by more highly qualified flautists. If this hole is made, it is the only one made diametrically in the bamboo; the Elema flautist has a supreme disregard for notes other than he can produce either from the hole, when made, or from blowing into his flute at one end by so placing that end that it may have the under lip as a cushion, and the upper lip free to cover as much of the hole as he deems necessary.

He has not yet evolved to that stage of appreciation which would enable him to distinguish the respective modulations of notes, hence he has not felt the need of making any effort to produce them. The foregoing native toy instruments are made by all the lads of all the Elema tribes, but the kavakava-the Haura name for Jew's harp-is made by the bush tribes only of this district.

I will endeavour to describe one $I$ have in my museum. It is made from a piece of bamboo which was carefully split in half. The half from which it was made measures, from end to end, $11 \frac{1}{4}$ inches. Its diameter is $1 \frac{1}{2}$ inches. 
At one end which, for convenience of description, we will term its "intact end" (for such it is apart from a hole in it, to which we shall ultimately refer, and a few scratches by way of ornamentation or sign of ownership), a length of $1 \frac{3}{4}$ inches has been reserved, and from it the medial line seems to have been carefully traced to the other end of the bambon. This medial line, proceeding from the intact end, is maintained to within an inch of the other end and cut off. From the intact end continuous fissures are made at equal distances along the remaining length of the bamboo, until the medial line is left as a tongue.

In appearance this primitive musical toy closely resembles an old-time fork of three prongs, having its outer prongs of equal widths and lengths, and its centre prong shorter and a shade narrower at its wider end and at the other end tapered to a point.

Through the hole in the intact end a piece of string, after being knotted at one end, is passed. With this twisted around his thumb and the other end of the instrument, with its hollow side inwards, placed horizontally between the performer's lips, by rapid twitching and jerking of the string a vibration of the tongue is produced and with it a sound not unlike that which comes from toy jews-harps at home.

\section{GAMES.}

If the children of Elema have not many toys, they certainly have an almost exhaustless stock of games, but we can only select a few from their stock for this paper.

1. Ikaroa.-Ikaroa is the generic name for snakes in all the dialects of the Ipi tribes of Elema.

Boys and girls play this game together. A ring is formed by the players joining hands after it has been duly arranged that the boys and girls are equally and alternately placed that each one in the game has a partner of the opposite sex. The ring being thus formed, one of the party begins to chant the following words in which all present join :-

\section{"Ikaroa uki lailai makeko, Seuseu haro, seuseu makeko, Ua sisi, mako sisi, ikaroa."}

Whilst chanting these lines in a monotone, the party swing their locked hands forward and backward until the last word is chanted, when they quiokly release hands, change partners, re-form the ring, and proceed again as above described.

No one seems able to translate these lines, notwithstanding many of the words are in every-day use.

2. Hohore--Hohore is the name of the Toaripi game of "hide and seek," which is played by the children of all the Elema tribes much in the same way as it is played by children at home. Two sides may be formed, one to hide, the other to seek, or it may be played by blindfolding one of the party as "blind-man's buff" is played at home.

VoL. XXXVIII. 
When the latter form of the game is played, it is usual to begin chanting whilst the individual is being blindfolded and to continue the chant "hohore mora keikei ; mai keikei hohore," until the object is found.

3. Helau heleiki vie is the Morea-ipi name of a game played by the small children of both sexes of this tribe, also by the children of all the ipi tribes of Elema, but known by different 'names by the respective tribes. With our present limited knowledge of child-life in the Gulf of Papua, this pastime, played during the northwest season, is quite unintelligible to us and unlike any game with which we are acquainted, but it affords the children of Elema amusement and delight difficult to describe on paper.

Prior to playing it, a table or stand is made on the beach. It has four legs, sticks about an inch in diameter, which are driven into the sand a depth of about 6 inches. About an inch down from the upper ends of these legs, cross sticks are lashed, and on this skeleton frame-work strips of sago bark are placed; the structure thus completed stands about 3 feet high, 4 feet long and $2 \frac{1}{2}$ feet wide.

The game itself takes the form of an unintelligible dramatic display. Little boys and girls take up their positions about the table and begin to dance, sway their bodies to and fro, and chant the following words :-

\section{" Auaua lei tiri maula, \\ Tivara, tivara tarapove, \\ Tari vaiva ivavuku terotero, \\ Tati vaiva ta, tati vaiva ta."}

Whilst swaying their bodies sideways and chanting the above lines, the little girls take in their hands the front part of their grass petticoats and flounce it continuously forward and backward; whereas the little boys content themselves with chanting and swaying their bodies and gesticulating with their hands.

The significance of this game is not known to the children or to the parents; the words of the chant do not give a satisfactory clue, but a fuller acquaintance with the dialect of the Morea-ipi tribe may yet enable us to trace in it a valuable bit of unwritten native history.

4. Swings.-No pastime affords greater pleasure to the lads and young men of Elema than the swing, and unlike many of their pastimes, it is practised alike by the $i p i$ tribes on the coast and the $a u, u$ and $r a$ tribes of the Elema hinterland. In every case the common object is gained, viz., the excitement derived from swinging through space, but the construction of these primitive swings is interesting and illustrative of the evolution of the swing.

The most primitive type of swing yet known to us in Elema is the one used by the Opau tribe residing a few miles inland of Kerema Bay.

A coconut tree or any other tree which overhangs a river or creek, is selected, and to it, at a considerable height from the ground, one end of a large and strong piece of rattan cane is suspended that its lower end may reach down about 3 feet from the ground. The swing is then complete and the excitement begins.

The ikauka or swing of the Morea-ipi tribe, residing at Orokolo, is a slight 
improvement on the above. Two trees, having a considerable lean toward one another, are selected, and, at a good height from the ground, a length of strong rattan cane is carefully tied to each of the two trees, at such a distance apart that when suspended the respective lengths are comfortably near one another at the lower end to avoid any inconvenience when being used as a swing.

The Opau lads, when swinging, set themselves going; not so with the Moreaipi lads. They take it in turns to give a send-off, and in this way; the individual, who has established his claim to the next swing by being first to seize the ends of the rattan cane, asks someone to give him a send-off, in other words one of the party stands between the suspended lengths of the rattan cane, crosses his arms by resting each elbow in the palms of opposite hand, so that his crossed arms may reach just below his chest. The send-off being taken from this human pedestal, the individual swings forward and backward with increasing velocity until he thinks he has attained sufficient force or rapidity to enable him, on the forward swing, to jump off and toe a mark beyond that made by his compeers.

The peroki, or swing of the Toaripians, so closely resembles the swing seen in local tea-gardens at home, that one may be inclined to think that the idea of its construction must have been taken from the suggestions of a foreigner, but the natives claim it as being their own from time immemorial.

The Toaripiaus require only one tree having a considerable lean over as, just above the bend of the tree, they lash horizontally a strong piece of wood. To this horizontal arm, about midway, they suspend the rattan cane by making a kind of noose knot, so that the cane, when suspended, may be in equal lengths. A seat or platform is then provided by placing the ends of the cane through the respective holes-bored about 6 inches from each end of the seat—of a piece of flat wood previously obtained and bored for this purpose. To secure the seat the ends of the cane, if long enough, are knotted, failing that, they are split, brought up over the seat at opposite angles and spliced to the main lengths.

In swinging, the Toaripians stand or sit on the seat, but with them, as with the Morea-ipians, the competitive spirit dominates, and each individual tries to make the longest jump from the swing when it is going at its swiftest.

5. Asi.-A large number of boys is needed to play this game properly, and they should be of varying height, so that the tall boys in the middle may easily be seen above the small boys of the outer circle. The arms of the boys are interlocked in such a way that when several of the boys wish to push in a particular direction they can combine their strength for that purpose. When all is ready, one boy, who acts as captain, sings out, "Look out! here comes a westerly squall." At that moment all the boys on the west line of the circle push with all their might. If they succeed in causing the opposite line to roll over, they claim that the westerly squall has wrecked the canoe. If they weather the westerly squall, the captain shouts, "Here is a south-east wind." And so they go on till they determine which is the strongest party on the asi, or canoe.

6. Isukakaroai.-This is really a contest of diving and swimming under water. 
Two sides are formed and the best swimmer under water of one side dives first; he has if possible to swim beyond the line of the other side. If he fails the best man of the opposing side makes the attempt, and so it goes on till the best side wins.

7. $K o \alpha$ is a game played only by very small children; having made pinnacles of sand on the beach, they make sand-balls and knock them over. [At Hula I saw small children making erections of sand on the beach.-A. C. H.]

8. Lavi.-This game is played in two ways: (1) as described by the late Rev. J. Chalmers in Pioneering in New Guinea (p. 183). (2) A number of boys stand with bent backs in a long line, the second boy having his hands on the shoulders of the first, and so on to the end of the line. The fun comes in when the end boy has to climb on the back of the one in front and walk erect along the line of arched backs without falling off. If he succeeds he escapes being walked over. So it goes on till the boys are tired or the game is played out.

9. Muru.-This game represents a woman going to her stack to get wood, and in doing so she is attacked by ants. A number of boys place their hands one on the other so as to form a stack of hands. This game is always played near to women's quarters, and there never fails a woman with a heart young enough to join in and give the boys pleasure. The stack of hands being raised the woman goes to get wood, and pulls at one or two hands, remarking what a grand pile of wood she has. Suddenly all the hands are freed, and the youngsters jump, buzz, and climb on the woman's back, and she escapes the best way she can, screaming, and shrieking that the ants are attacking her.

The foregoing notes on "Toys and Games of Elema" embrace all the toys known to the children of Elema, but they have a score or more of games which, for lack of time and a limited knowledge of the same, I am unable to include in this paper. 